\title{
Our first experience of an ethics committee: entering the Dragon's Den
}

A recent editorial in the $B M J$ proposes that undergraduate researchers face significant barriers in the form of ethics and NHS research governance approval procedures which are bureaucratic, excessive, and de-motivating. ${ }^{1}$ As medical students who had to negotiate the system for our Primary Healthcare intercalated $\mathrm{BSc}^{2}$ this academic year, we could not agree more. In addition to the unnecessary red-tape involved, our very first experiences of the procedure were frankly distressing and demoralising. Our account should serve as a timely reminder of why fledgling researchers may be put off in pursuing their interests in fields which are already starting to suffer.

We were called to our ethics meeting on a particularly cold February evening; perhaps the weather should have forecast the bitter encounter that lay ahead. For 40 minutes we waited on wooden chairs outside the committee's room until the student who was unaccompanied by a supervisor was sent for. I present my experience of the meeting.

Following the older gentleman wearing a bow tie who had summoned me, it seemed as if he had stepped directly out of one of the grand portraits of austere faces on either side of the corridor we walked down. A long table with eleven grim faces awaited me as I entered the meeting room. There was no attempt to make me feel comfortable apart from a brief effort by the chairman to build rapport by commenting favourably on my academic record. Introductions aside, I suddenly became the target of a volley of questions. Other than the occasional nod of a head, there was little contribution from the other committee members. The committee's main contention with the small study in general practice that I wished to conduct was that I promised participants confidentiality but reserved the right to breach it should malpractice occur. They proposed the view that students had no business in raising concerns regarding the treatment of patients when acting the role of a researcher. However, this goes against the General Medical Council's guidance that all medical students, as doctors in training, have the same obligations when carrying out research studies as they do in their capacity as medical students, including acting in the patient's best interest. $^{3}$

The same identical issue was raised in the second student's meeting. Here, the supervisor became the unfortunate victim of an aggressive interrogation by the chairman. The only other contribution from the rest of the committee was when one member asked whether the qualitative study would be 'controlling for variables.' As novel researchers, the irrelevance of the questioning given the study design was obvious. This compounded our doubts about the integrity and credibility of the committee who sat before us. The rest of the meeting was filled with similar illogical questions.

At times, the tone of the ethics committee was mocking in nature and the experience is not one we would wish to repeat. The discourteous and unprofessional behaviour endured by us and other students in the past ${ }^{4,5}$ is a significant barrier in encouraging us to proceed with research in the future. Taking into account the relative simplicity of the studies we had proposed, the hostility and responses we encountered from the committee seem even more baffling.

Finally, as we left the 'Dragon's Den', we encountered an interesting if not slightly farcical situation. A young junior doctor eagerly sat outside the door awaiting his turn to face the committee. New to the field of research, he proudly described his study to us; it involved speaking to homosexual males about their sexual behaviour and lifestyle. The same naïve enthusiasm we had walked in with was apparent on his face. We exchanged knowing glances; oh, to be a fly on the wall for his hearing.

\section{Jagdeep Sandhu and Nyla Khan}

\section{REFERENCES}

1. Rees, M, Wells, F. Falling research in the NHS. BMJ, 2010; 340: c2375.

2. UCL Research Department of Primary Care and Population Health. iBSC in Primary Care. London: UCL, 2009.

http://www.ucl.ac.uk/pcph/education/undergrad/bsc _pcl (Accessed 26 Nov 2010).

3. GMC. Medical students: professional values and fitness to practise. London: General Medical Council 2009. http://www.gmc-

uk.org/static/documents/content/GMC_Medical_Stu dents.pdf (accessed 26 Nov 2010).

4. Tan SP. My disappointment with an ethics committee. BMJ, 2004; 329: 807.

5. Dennis, M. My disappointment with an ethics committee (rapid response). BMJ, 2004; 329: 807.

DOI: 10.3399/bjgp11X549117 